\title{
Bradyarrhythmias in acute myocardial infarction: should thrombolysis lower the decision threshold for temporary pacing?
}

\author{
C.W. Lim, M.J. Bennie and R. Lim \\ Royal Adelaide Hospital, South Australia, Australia and Royal Liverpool Hospital, Liverpool, UK
}

\begin{abstract}
Summary: Both acute myocardial infarction and reperfusion therapy with thrombolytic agents may be associated with bradyarrhythmias, and there may be a case for 'prophylactic' insertion of a temporary pacing wire in selected patients. We describe 4 patients in whom clinical decisions had to be made concerning the appropriateness and timing of temporary pacing, and discuss the implications for modern guidelines on the indications for pacing in such a setting.
\end{abstract}

\section{Introduction}

Acute myocardial infarction may be associated with bradyarrhythmias which can be transient and self-limiting or immediately life-threatening. ${ }^{1}$ Such bradyarrhythmias may range from sinus bradycardia, as in inferoposterior infarction due to activation of the Bezold-Jarisch reflex, through complete atrioventricular block, to ventricular standstill. Furthermore, coronary reperfusion by thrombolysis has been reported to induce bradyarrhythmias and may also aggravate any tendency to such rhythm or conduction disturbances. ${ }^{2-5}$ We describe 4 cases of acute myocardial infarction in which this complication influenced the decision whether or not to use intravenous thrombolytic therapy, and discuss the implications for widening the indications for temporary cardiac pacing in this, not uncommon, clinical setting.

\section{Case reports}

Case 1

On admission, the electrocardiogram (ECG) of a hypertensive 50 year old man on a beta-blocker showed acute inferior infarction and complete heart block with a ventricular rate of 38 beats $/ \mathrm{min}$. This was well-tolerated by the patient whose blood pressure remained above $110 / 90 \mathrm{mmHg}$. The decision was taken by the admitting team to continue

Correspondence: R. Lim, M.R.C.P., Department of Cardiology, St. Bartholomew's Hospital, London EClA 7BE, UK.

Accepted: 14 January 1991 haemodynamic observation and withhold thrombolytic therapy in case transvenous pacing became necessary. By the time his conduction spontaneously improved to first degree atrioventricular block and then sinus rhythm, 6 hours had lapsed, inferior $Q$ waves were apparent, and thrombolysis was no longer felt appropriate. His peak serum creatine kinase activity was $1560 \mathrm{IU}$ (normal $<200$ ) and subsequent radionuclide measurement showed a left ventricular ejection fraction of $35 \%$.

Case 2

A 50 year old man, whose angina had recently become unstable, was admitted with an acute inferior infarct and first degree heart block with a rate of 60 beats $/ \mathrm{min}$. Within 2 hours of onset of pain, he received thrombolytic therapy and promptly developed complete heart block with a ventricular rate of 40 beats $/ \mathrm{min}$ and blood pressure of $80 / 60 \mathrm{mmHg}$. Thrombolytic administration was immediately stopped. He then went into ventricular fibrillation. Electrical defibrillation returned his rhythm to complete heart block and he required transvenous pacing for 4 days. His subsequent course was uneventful.

\section{Case 3}

A 56 year old woman presented with chest pain, dyspnoea, sinus bradycardia and hypotension. Her ECG showed ST elevation in II, III, aVF, V1, V3 and V4, and depression in I, aVL and V2. Clinically she had right ventricular as well as inferior left ventricular infarction. Soon after admission, her rhythm alternated between first degree and Wenck- 
ebach block. Insertion of a temporary pacing wire via an infraclavicular subclavian approach proceeded swiftly followed by thrombolytic therapy. The same day, she developed complete heart block. Despite chronotropic, inotropic and circulating volume support, she died 2 days later from progressive loss of cardiac output.

\section{Case 4}

A 53 year old woman presented within 1 hour of the onset of chest pain. Her admission ECG showed hyperacute anterior ST elevation and intermittent Wenckebach block. Despite haemodynamic stability, it was decided to insert a prophylactic temporary pacing wire, followed promptly by thrombolytic therapy. Intermittent second degree block progressed to complete heart block several hours later, but this resolved within 24 hours. Subsequent ECGs showed well-preserved anterior $R$ waves, and pre-discharge angiography revealed patent coronary arteries and no significant myocardial damage.

\section{Discussion}

Thrombolytic treatment has become accepted as an essential part of the routine management of acute myocardial infarction. Its true impact on the incidence of bradyarrhythmias complicating acute infarction is unknown, but there is little doubt that the above cases are not rare occurrences in clinical practice. Where the indication for temporary pacing is well-defined, as in complete heart block with haemodynamic compromise, this should take precedence over the intravenous administration of thrombolytic therapy. However, if transvenous pacing, whether via the subclavian, jugular, antecubital or femoral approach, can be achieved by an experienced operator without trauma or delay, there is no reason why thrombolysis should not get underway immediately. In this regard, the ease of administration of anistreplase (APSAC, anisoylated plasminogen-streptokinase activator complex) may be advantageous.

In other cases of rhythm or conduction disturbance where the role of temporary pacing has

\section{References}

1. Rosenfeld, I.F. Bradyarrhythmias, abnormalities of conduction, and indications for pacing in acute myocardial infarction. Cardiol Clin 1988, 6: 49-61 .

2. Goldberg, S., Greenspon, A.J., Urban, P.I. et al. Reperfusion arrhythmia: a marker of restoration of antegrade flow during intracoronary thrombolysis for acute myocardial infarction. Am Heart J 1983, 105: 26-32. traditionally been contentious, ${ }^{1,6,7}$ the advent of thrombolytic therapy has created awkward clinical scenarios. In the average general hospital, it is arguably safer to pace before than after thrombolysis is started. However, coronary thrombolysis is of greatest benefit the earlier it is achieved, and yet the first few hours of myocardial infarction is the period when rhythm or conduction disturbances may be most transient ${ }^{8}$ and thus not require pacing unless poorly tolerated.

Should such proven and potentially life-saving therapy be delayed or even withheld for fear of aggravating potentially life-threatening bradyarrhythmias for which the treatment of transvenous pacing is invasive and therefore possibly dangerous? Bradyarrhythmias are associated with a higher in-hospital mortality,10 and this is partly due to greater loss of myocardium. ${ }^{11,12}$ The potential benefits of thrombolysis are greater the larger the amount of myocardium threatened by infarction, yet these are the cases in whom bradyarrhythmias may be more common and haemodynamically significant. In such situations, the shorter half-life of recombinant tissue plasminogen activator may allow a greater safety margin should invasive pacing be undertaken.

Now that coronary thrombolysis is widespread, the occasional use of acute anti-arrhythmic ${ }^{13}$ or beta-blocker ${ }^{14}$ treatment provides yet another reason for broadening the accepted indications for temporary pacing. Indeed, in some patients, there may be a strong case for 'prophylactic' pacing to avoid the potential deleterious effects of provocation or aggravation of conduction disturbances. However, in such cases where the threshold for deciding on temporary pacing may be lowered, the insertion of a pacing wire should probably not be allowed to delay the administration of thrombolytic agents. Noninvasive temporary transcutaneous pacing may assume some importance in such situations. ${ }^{15}$ Pending revised guidelines on the indications for temporary pacing in acute myocardial infarction and clarification of the medicolegal implications, decisions in the acute setting can only continue to be based on clinical experience and judgement, and admitting doctors should become familiar with various routes of transvenous pacing.

3. Wei, J.Y., Markis, J.E., Malagold, M. \& Braunwald, E Cardiovascular reflexes stimulated by reperfusion of ischemic myocardium in acute myocardial infarction. Circulation 1983, 67: 796-801.

4. Esente, P., Giambartolomei, A., Gensini, G.G. \& Dator, C. Coronary reperfusion and Bezold-Jarisch reflex (bradycardia and hypotension). Am J Cardiol 1983, 52: 221-224. 
5. Koren, G., Weiss, A.T., Ben-David, Y., Hasin, Y., Luria, M.H. \& Gotsman, M.S. Bradycardia and hypotension following reperfusion with streptokinase (Bezold-Jarisch reflex): a sign of coronary thrombolysis and myocardial salvage. Am Heart J 1986, 112: 468-471.

6. Hindman, M.C., Wagner, G.S., Jaro, M. et al. The clinical significance of bundle branch block complicating acute myocardial infarction. Circulation 1978, 58: 679-699.

7. Lewin, R.F., Kusniec, J., Sclarovsky, S. et al. Alternating Wenckebach periods in acute inferior myocardial infarction: clinical, electrocardiographic, and therapeutic characterization. PACE 1986, 9: 468-475.

8. Feigl, D., Ashkenazy, J. \& Kishop, Y. Early and late atrioventricular block in acute inferior myocardial infarction. J Am Coll Cardiol 1984, 4: 35-39.

9. Lassers, B.W. \& Julian, D.G. Artificial pacing in the management of complete heart block complicating acute myocardial infarction. Br Med J 1968, 2: 142-146.

10. Nicod, P., Gilpin, F., Dittrich, H., Polikar, R., Henning, H. \& Ross, J.Jr. Long-term outcome in patients with inferior myocardial infarction and complete atrioventricular block. $J$ Am Coll Cardiol 1988, 12: 589-594.
11. Strasberg, B., Pinchas, A., Arditti, A. et al. Left and right ventricular function in inferior acute myocardial infarction and significance of advanced atrioventricular block. Am J Cardiol 1984, 54: 985-987.

12. Opolski, G., Kraska, T., Ostrzycki, A., Zielinski, T. \& Korewicki, J. The effect of infarct size on atrioventricular and intraventricular conduction disturbances in acute myocardial infarction. Int J Cardiol 1986, 10: 141-147.

13. Edvardsson, N., Holmberg, S., Talwar, K.K. \& Olsson, S.B. Electrophysiological effects of lidocaine in acute myocardial infarction with bifascicular block or complete A-V block. Cardiology 1983, 70: 333-340.

14. ISIS-1 (First International Study of Infarct Survival). Collaborative Group: Mechanisms for the early mortality reduction produced by beta-blockade started early in acute myocardial infarction: ISIS-1. Lancet 1988, i: 921-923.

15. Madsen, J.K., Meihom, J., Videhak, R., Pedersen, F. \& Granda, P. Transcutaneous pacing: experience with the Zoll noninvasive temporary pacemaker. Am Heart $J$ 1988, 116: $7-10$. 